\title{
Blandness, Bathos, or Brashness? \\ Choosing Pathways to Validity and Relevance for Chinese Politics Research
}

\section{William Hurst}

The study of Chinese politics and society has reached a crossroads. A year ago I called for scholars to eschew exclusive focus on the current 'methods arms race' and engage in more cross-national comparative analysis to bring the study of Chinese politics out of isolation (Hurst 2018). Upon further reflection, however, it seems the choice we face is actually more complex and nuanced. Two shifts have changed the way we must approach data collection and left us with three main alternatives: blandness, bathos, and brashness.
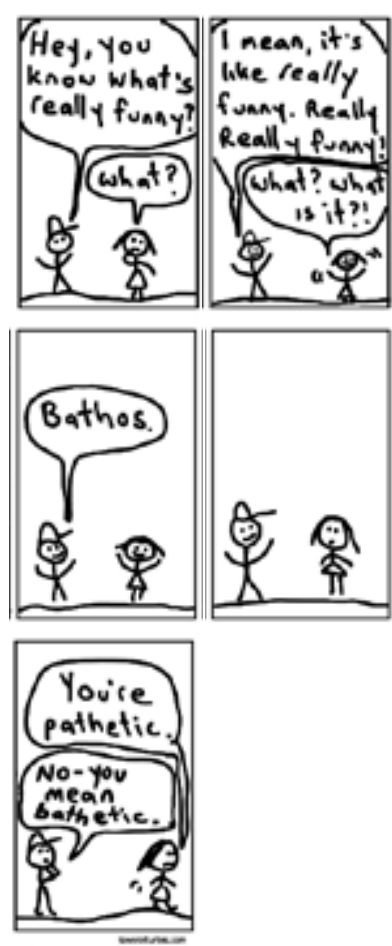

PC: towerofturtles.com
As many have remarked, certain kinds of field research have become substantially more challenging in China. The research environment has tightened to such an extent that many feel it is no longer feasible to rely principally on direct observations, onthe-ground interviews, or access to government-administered archives to study key phenomena in contemporary Chinese politics and society. What had been the main avenues for research since China opened up in the 1980s are increasingly closing.

At the same time, tremendous flows of new data and sources have poured forth from China. These have come especially as new first-rate scholarship by mainland-based scholars, newly available documents and historical data, new quantitative data sets, and newly digitisable text or other content-frequently, though by no means exclusively-online. On top of this, many thousands of long-available sources-from Red Guard documents to official histories and other publications-remain on shelves or in storage in places like Berkeley and Ann Arbor, mostly untouched and unused, just waiting for scholars to rediscover them.

Taken together, these shifts force us to adjust how we gather our data and what sorts of information and sources we seek. But we indubitably enjoy a much greater overall abundance of raw material for research than did previous generations of scholars. 


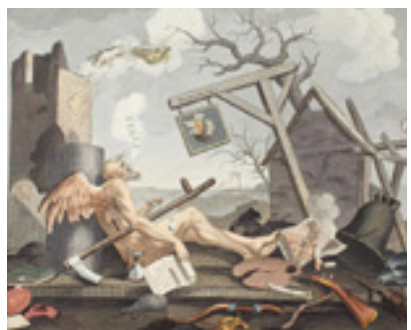

The bathos, or manner of sinking, in sublime paintings, inscribed to the dealers in dark pictures. Designed and engraved by William Hogarth. PC: Library of Congress
Classically, we find bathos in a literary text when an author works up a great lather of passion and erudition, only to leave the reader with a trite or ridiculous conclusion.
Dealing with this 'new normal' crucially means choosing between different ways of grappling with the new data, even as we cope with the loss of access to more and more of the old.

The most straightforward choice is the blandness of 'mere' description. Descriptive research is limited by its lack of theoretical innovation or explanatory claims. But it can also be essential for our baseline understanding of critical processes and phenomena. Drawing on troves of new data or sources-be they documentary/archival, quantitative, or even scraped-to fill in lacunae or correct mischaracterisations in prior work is immensely valuable and never boring to worthy readers. Such description, however, is only able to propel the field forward in small hops-no great leaps-and is therefore likely much better suited to articles or reference works than books (importantly, bland work on its own probably also cannot form the core of a successful tenure or promotion dossier for a social scientist). Still, without backfilling areas we thought we knew or had previously passed over in ignorant silence, we are left with incomplete, and perhaps in some cases incorrect, accounts as the foundations of our current understandings, assumptions, and projects, forever stunting our future development.

Classically, we find bathos in a literary text when an author works up a great lather of passion and erudition, only to leave the reader with a trite or ridiculous conclusion-ending a seemingly epic story with a whimpering crestfallen squib, rather than a gratifying bang. Much methods-driven research on contemporary China that leverages new data to test smallbore hypotheses from other fields can be similar. What one colleague calls 'one-sentence findings' are prefaced with a lot of what another refers to as 'methodological heavy breathing', only to fail to measure up to the hype. This problem is worst in bathetic books. But the strengths of the paradigm can shine through in articles, and such work both makes our field more systematic and subjects some basic claims to vital scrutiny facilitated by new sources and sophisticated techniques.

Bathetic articles may be too bedizened with technical bling for some tastes, but they are essential if we are to have confidence in the validity of our causal claims. Only this approach allows the sort of hypothesis testing that much of contemporary social science demands. And only this type of work can engage directly and intelligibly with certain disciplinary debates from which the study of China has for too long been isolated. 
So, where does this leave us? Are we still a field in need of a curative cleanse and a brash turn toward cross-national comparison, concept and theory building, or radical leaps up the ladder of generality? Yes.
Going brashly out on a limb to build new concepts and theories, taking the aleatory risk that they may prove wrong, is the final option. Even when brash work succeeds, it necessarily steps beyond the bounds of what may be demonstrated unassailably by the latest techniques and its validity may remain in dispute. There are many ways to pursue brash work and all of them also involve leveraging new data and sources. But they, critically, do not rely only on new data to carry the day or on its use to test limited hypotheses taken off the shelf. Rather, they at least endeavour to help the study of China become a 'producer field' by generating concepts and theoretical insights that might travel to other contexts (Reny 2011).

One brash approach is to engage in cross-national comparisons-as I called for last year (Hurst 2018). Another is to focus on concept formation, crafting new ways to understand already established facts and patterns of Chinese politics or society, perhaps with new wrinkles revealed by recently uncovered data or sources. A third is to confront established ideas with new facts to make generalisable claims about China that are both more accurate to its context and potentially more portable to others. Any of these three requires a certain bumptious chutzpah that may be off-putting to some bland or bathetic proponents or practitioners. If bathetic work can be overwrought, brash research has a clear tendency to over-claim. It is also almost always better suited to books than most types of articles-though new concepts can sometimes be introduced in articles, even they are usually best fleshed out in books. The article format simply lacks the space and scope to introduce bold new ideas and to elaborate their nuances and generalisability by applying them to empirical contexts. Similarly, only books provide sufficient range to allow authors both to develop new theoretical frameworks and to explore their implications fully across multiple deeply researched cases.

So, where does this leave us? Are we still a field in need of a curative cleanse and a brash turn toward cross-national comparison, concept and theory building, or radical leaps up the ladder of generality? Yes. But we need not abandon all bathetic hypothesis testing. Instead, we need only recognise the strengths and weaknesses of each approach and ensure that each enjoys pride of place in specific types of publication venues. We must also recognise that almost no single piece of research can likely incorporate healthy measures of all three approaches. In fact, no single researcher in his or her career is likely to master all three paradigms equally. 
To use a different analogy, the abundance of fruit that now lies upon the ground is of many different species, distinct from those that older scholars had been fond of characterising as 'lowhanging'
The best and most innovative research must walk on two legs, even if it shies away from great leaps. Good books and articles of general interest must engage new streams of data and make gains for either methods and rigour or theory and concepts. Researchers pursuing a strategy of bathos should concentrate on disciplinary or generalist journals for their primary outlets (as indeed many such researchers already do). Most brash work is similarly not as well suited to articles and rightly demands full elaboration in monograph form. Finally, we must not forget about the bland orphan of descriptive scholarship that simply brings new or better data to bear on previous gaps or thinlybased conventional wisdom. Such research, even if it doesn't anchor any individual's career, deserves a home in area studies journals, which actually used to publish a great deal of it.

We do not have to make an exclusive choice-and indeed we do so at our peril. Instead, we must ensure a coexistence of the three forms if we are to become a theory-producing corner of the discipline that also takes full advantage of our comparative advantages and all available data to assess causal relationships with clear-eyed precision, while keeping ourselves grounded in the fullness of the country we are all groping at different parts of the elephant to understand (Baum and Shevchenko 1999).

To use a different analogy, the abundance of fruit that now lies upon the ground is of many different species, distinct from those that older scholars had been fond of characterising as 'low-hanging' (O'Brien 2006, 38). Moreover, more and more trees in the orchard are being ring-fenced, leaving most wouldbe climbers and pickers to glean what they can from the vast bounty at their feet. Just picking up, tasting, and describing new kinds of fruit can be extremely valuable, even if it seems milquetoast to many social scientists.

Similarly, using new fruits to complement or augment recipes taken off the shelf from remote parts of the disciplines can help improve and refine those, even if the new improvements to dishes strike some as unimaginative or jejune. Finally, the daring can use the new ingredients to craft new recipes out of whole cloth, but while running the non-trivial risk that the resulting creations prove unpalatable to the point of producing more dyspepsia than insight. It is time for all of us to recognise the choice we face, and then for each of us to choose a path forward and accept the baggage we take on as we walk it. 